\title{
Some Coccidial Parasites of the Lizard Amphisbaena alba (Reptilia: Amphisbaenia: Amphisbaenidae)
}

\author{
Ralph Lainson
}

Departamento de Parasitologia, Instituto Evandro Chagas, Av. Almirante Barroso 492, 66090-000 Belém, PA, Brasil

Five parasites are described in the lizard Amphisbaena alba (Amphisbaenidae) from the state of Pará, North Brazil. Mature oocysts of Choleoeimeria amphisbaenae $n$. sp., are passed already mature in the faeces. They are ellipsoidal-cylindrical, average $33.7 \times 22.8 \mu \mathrm{m}$ and are devoid of micropyle, oocyst residuum or polar body. The colourless wall is smooth and of 2 layers. The 4 dizoic sporocysts have no Stieda body and average $13 \times 9.3 \mu \mathrm{m}$. Endogenous stages develop in the epithelial cells of the gall-bladder in the manner described for the genus and may cause extensive tissue damage. Sporulation of Isospora capanemaensis $n$. sp., is completed 3 days after the oocysts are voided in the faeces. They average $14.8 \times 14.5 \mu \mathrm{m}$ and have no micropyle, oocyst residuum or polar body. The 2 tetrazoic sporocysts are pear-shaped, average $8.6 \times 6.6$ and have an inconspicuous Stieda body. Endogenous development is in the epithelial cells of the ileum, and heavy infections cause considerable tissue destruction. Multisporocystic oocysts passed in the faeces of one A. alba possibly originated from an invertebrate host ingested by the lizard. A globidium-like cyst in the digestive tract of $\mathrm{A}$. alba measured $105 \times 85 \mu \mathrm{m}$ and contained many hundreds of merozoites. A stained kidney smear of the same lizard revealed the presence of an unidentified parasite producing multinucleate cyst-like stages.

Key words: Coccidia - Amphisbaena alba - lizard - Choleoeimeria amphisbaenae n. sp. - Isospora capanemaensis n. sp. globidium - unidentified parasites - Brazil

Species of the legless lizard Amphisbaena (Reptilia: Amphisbaenia: Amphisbaenidae) are found in the forested lowlands of continental South America, Panama, and the Caribbean islands (Peters \& Donosco-Barros 1970). Forty-five species have been described, although some of these are considered to have been insufficiently characterized.

Three species are recorded from the Amazon Region of Brazil. In addition to anatomical differences they are readily recognized by their colouration. A. alba Linnaeus is of a uniform yellowish-cream colour, A. fuliginosa Linnaeus is white with a variable number of black spots, and A. mitchelli Procter is grayish-pink dorso-laterally, with a clear pinkish ventral surface.

$A$. alba, the subject of this study, has a wide distribution from Panama, through Venezuela and the Guianas, Colombia, Peru and Bolivia east of the Andes, Brazil, Northern Paraguay and Trinidad. In the Amazon region of Brazil it is a common reptile, but its burrowing habits, and the fact that it is rarely encountered above ground, gives a misleading impression of rarity. It is frequenttly found in the nests of the "saúva", the fungus-ant Atta sexdens, where it doubtless consumes the larval stages, and this has led to a local name of "mãe de saúva" ("mother of the saúva"). Difficulty for the untrained eye in distinguishing the animal's head from its tail has given

Financial support: Wellcome Trust, London, grant 066445 Fax:+55-91-226.1284. E-mail: ralphlainson@iec.pa.gov.br Received 31 July 2003

Accepted 10 September 2003 rise to another common name of "cobra de duas cabeças" ("snake with two heads"). As with most snake-like creatures, the bite of $A$. alba is wrongly assumed by many to be of a venomous nature and, in addition, there exists the strange local belief that it can also sting with its tail.

Parasitic protozoa of $A$. alba have been poorly studied and, as far as I am aware, the only one recorded from this reptile is a haemogregarine. It was given the name of Haemogregarina amphisbaenae Pessôa, 1968, but most probably does not belong to this genus. Telford (1984) mentions the finding of what was probably the same parasite in a single specimen of A. alba from Venezuela, but gave no description. I have examined thin blood films from 43 of these lizards, from various localities in Pará, North Brazil, without encountering this haemogregarine (unpublished observations).

A recent examination of faeces from $A$. alba has revealed the presence of 3 morphologically different coccidial oocysts. Two of these parasites are considered as new species of Choleoeimeria and Isospora, and a description is given of their endogenous stages in the epithelial cells of the gall-bladder and ileum respectively. Oocysts of the third type were multisporocystic/dizoic and no endogenous stages attributable to this coccidian were found in lizards that had passed them. Two other parasites are described: one producing a large globidium-like cyst in the lamina propria of the small intestine, and another forming multinucleate, cyst-like bodies in the kidney. The exact nature of both organisms has yet to be determined.

\section{MATERIALS AND METHODS}

Specimens of $A$. alba were maintained, on a diet of laboratory-reared Tenebrio larvae and adults, in clean glass aquaria. Suspensions of faecal material were made in $2 \%$ aqueous potassium dichromate solution $\left(\mathrm{K}_{2} \mathrm{Cr}_{2} \mathrm{O}_{7}\right)$ and 
kept in covered Petri dishes at approximately $24-26^{\circ} \mathrm{C}$. They were examined for the presence of coccidial oocysts using normal light microscopy, x 16 and x 40 objectives and $\mathrm{x} 10$ eyepieces; positive samples were checked daily to determine the sporulation time of any oocysts detected. All measurements were made with an eyepiece micrometer and the oil immersion lens. They are given in $\mu \mathrm{m}$ as means, followed by the range in parentheses, the shape index (ratio of length/width) and the number measured (n) Photomicrographs were made using a Zeiss "Photomicroscope III" and Kodak TMX 100 film.
Blood was obtained by cardiac puncture and thin films were rapidly air-dried, fixed in absolute methyl alcohol and stained by Giemsa's method. Dab smears of tissues from autopsied specimens were treated in the same manner. Bile was removed from the gall-bladder with a finely drawn glass pipette and examined for the presence of oocysts. The entire gall-bladder of each animal was then fixed in $10 \%$ neutral formol-saline, together with portions of liver, spleen, kidney, lung, and intestine. Histological sections of tissues embedded in paraffin wax were cut at $4 \mu \mathrm{m}$ and stained with haematoxylin and eosin.

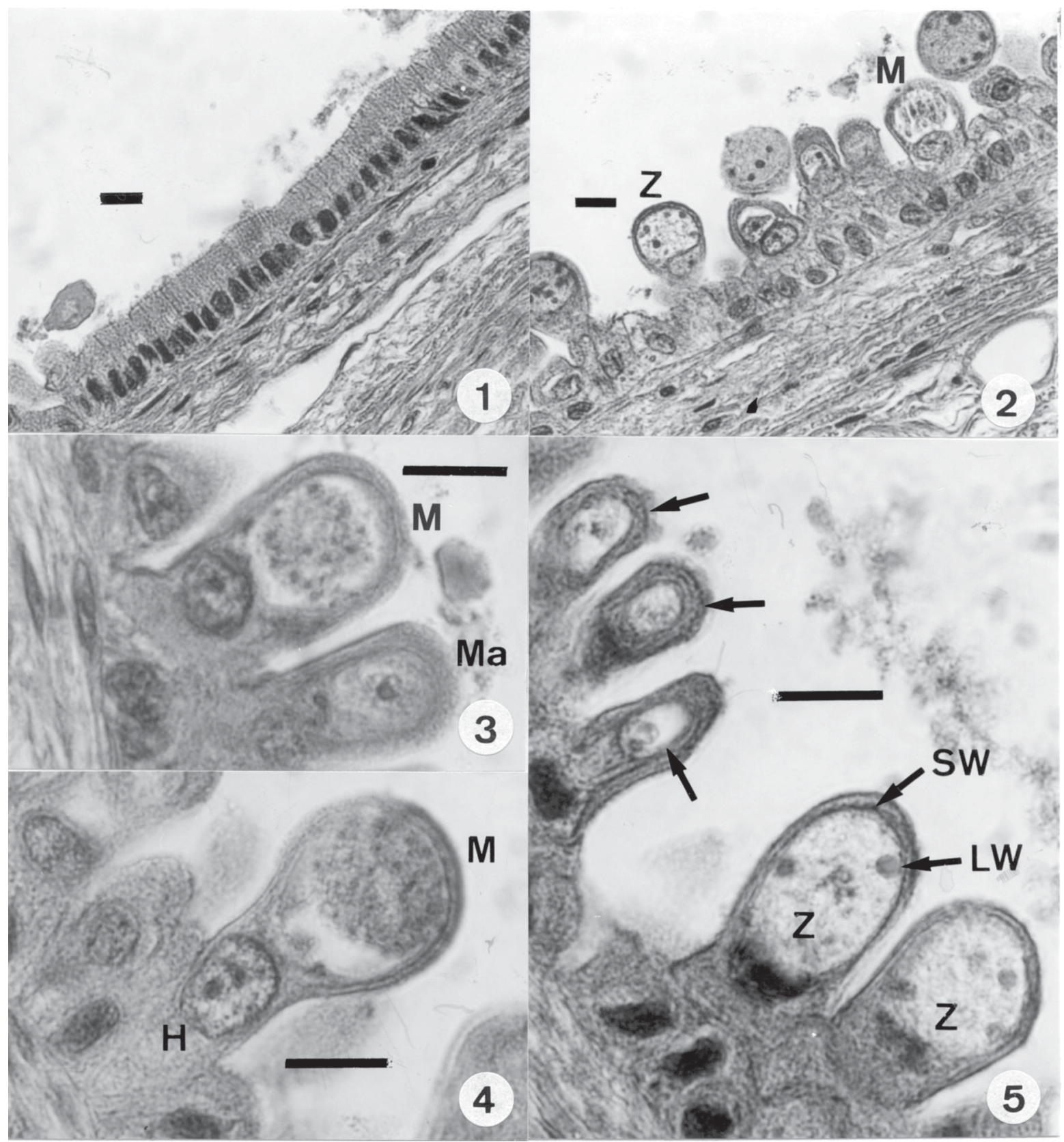

Figs 1-5: Choleoeimeria amphisbaenae n. sp. in the gall-bladder epitheliium of the lizard Amphisbaena alba. Fig. 1: low power view of normal epithelium in an uninfected lizard. Fig. 2: low power view showing intense infection, with displacement of infected cells into the lumen of the gall-bladder (M: segmented meront; Z: zygote). Fig. 3: developing meront (M) and macrogamont (Ma). Fig. 4: maturing meront: note stalk-like protrusion of the host cell $(\mathrm{H})$, containing the hypertrophied host cell nucleus. Fig. 5: very young meronts (arrowed) and two zygotes, or young oocysts (Z), with small and large wall-forming bodies (SW and LW). Sections stained with haematoxylin and eosin. Bars: $10 \mu$ 


\section{RESULTS}

Choleoeimeria amphisbaenae n. $\mathrm{sp}$

(Figs 1-9; 29)

Description of the oocyst: mature forms 33.7 x 22.8 (3037 x 20 - 26), shape index $1.5(1.2-1.7), \mathrm{n}=25$. Ellipsoidal to cylindrical and often slightly curved. Oocyst wall smooth and colourless, about 1.0 thick and with no micropyle or striations. It is of 2 layers: an outer, very fine membrane and a thicker inner one. The outer layer occasionally becomes lifted off in some areas, to form small bleb-like protrusions. No oocyst residuum, polar body or other inclusions. The 4 dizoic sporocysts average $13 \times 9.3(11.8-14$ x $9-10)$, shape index $1.4(1.2-1.5), \mathrm{n}=$ 35. They are broadly ellipsoidal, with no Stieda body or other localized thickening of the very thin wall. Sporozoites, with conspicuous posterior and anterior refractile bodies, curve around a residuum composed of relatively large globules. With age, or pressure under a coverslip, the sporocysts frequently dehisce and leave the sporozoites free in the oocyst.

Endogenous stages: merogony and gametogony stages develop in the epithelial cells of the gall-bladder in the characteristic manner described for the genus (Paperna $\&$ Landsberg 1989). The parasites are at first localized immediately below the brush border of the epithelial cells, which become hypertrophied and displaced into the gallbladder lumen (Fig. 2). The infected cells remain attached to the basal membrane by a stalk-like protrusion. In histological sections, the youngest parasites seen measured $4 \times 3$,

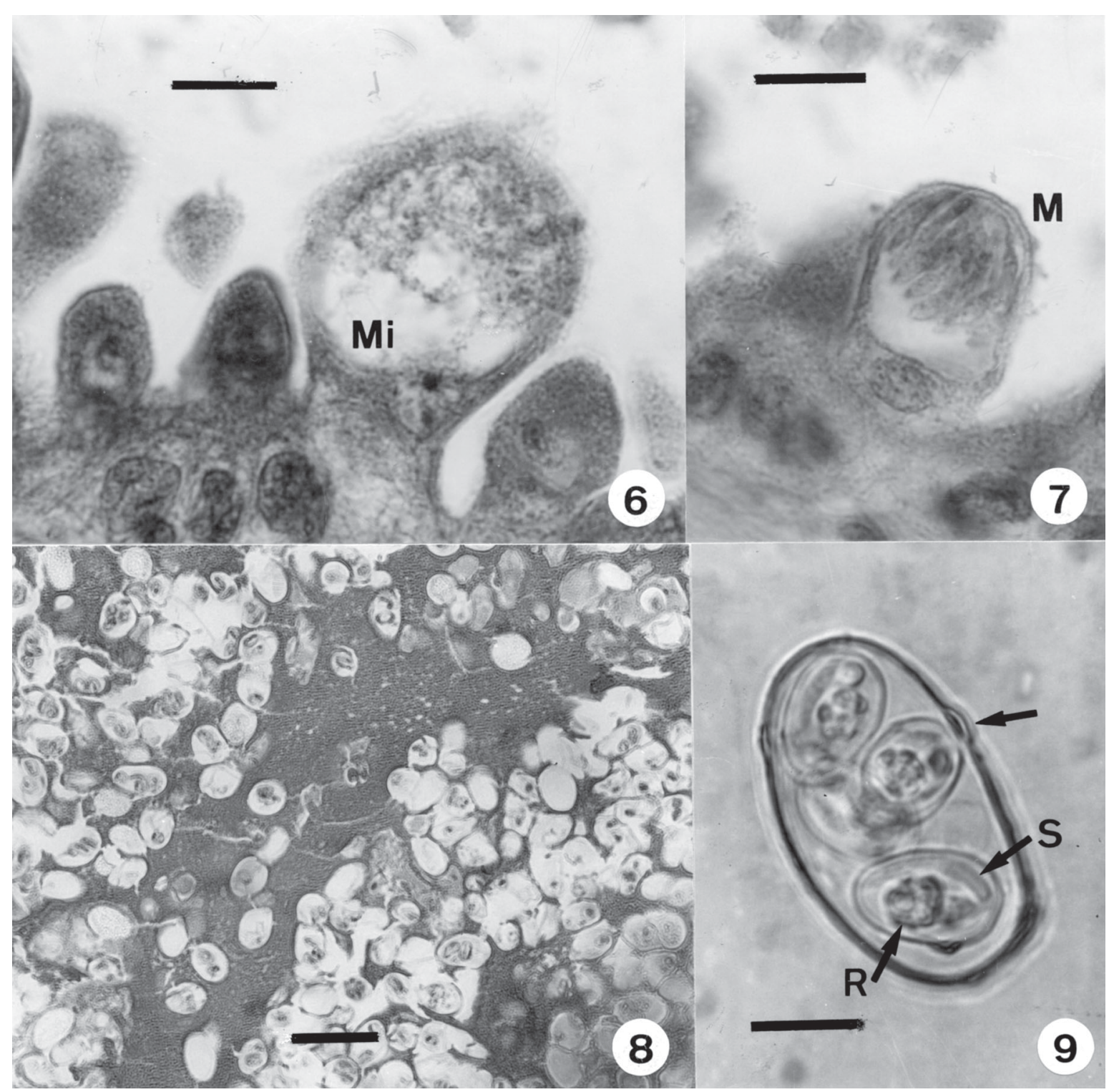

Figs 6-9. Choleoeimeria amphisbaenae n. sp. in the gall-bladder epithelium of the lizard Amphisbaena alba. Fig. 6: nearly mature microgamont (Mi). Fig. 7: mature, segmented meront (M). Fig. 8: low power view showing enormous number of mature oocysts in the lumen of the gall-bladder. Fig. 9: living, mature oocyst in the bile: note separation of the two wall layers (arrowed). S: sporozoite; R: sporocyst residuum. Bars in Figs 6, 7, 9: $10 \mu \mathrm{m}$; bar in Fig. 8: $50 \mu \mathrm{m}$. Figs 6-8: sections stained with haematoxylin and eosin. 
contained a single nucleus, and occupied a prominent parasitophorous vacuole. Young meronts with 2 or 3 nuclei measured $5 \times 4$ (Fig. 5), growing to about $15 \times 14$ with from 10 -12 nuclei (Figs 3,4). Segmented meronts were of similar size and produced a comparable number of merozoites (Figs 2, 7).
Mature microgamonts measured approximately $25 \times 20$ and were estimated to produce over 50 microgametes (Fig. 6). Young macro-gamonts are ovoid to spherical, with a prominent nucleus and nucleolus (Fig. 3). With growth, a peripherally disposed ring of small wall-forming bodies

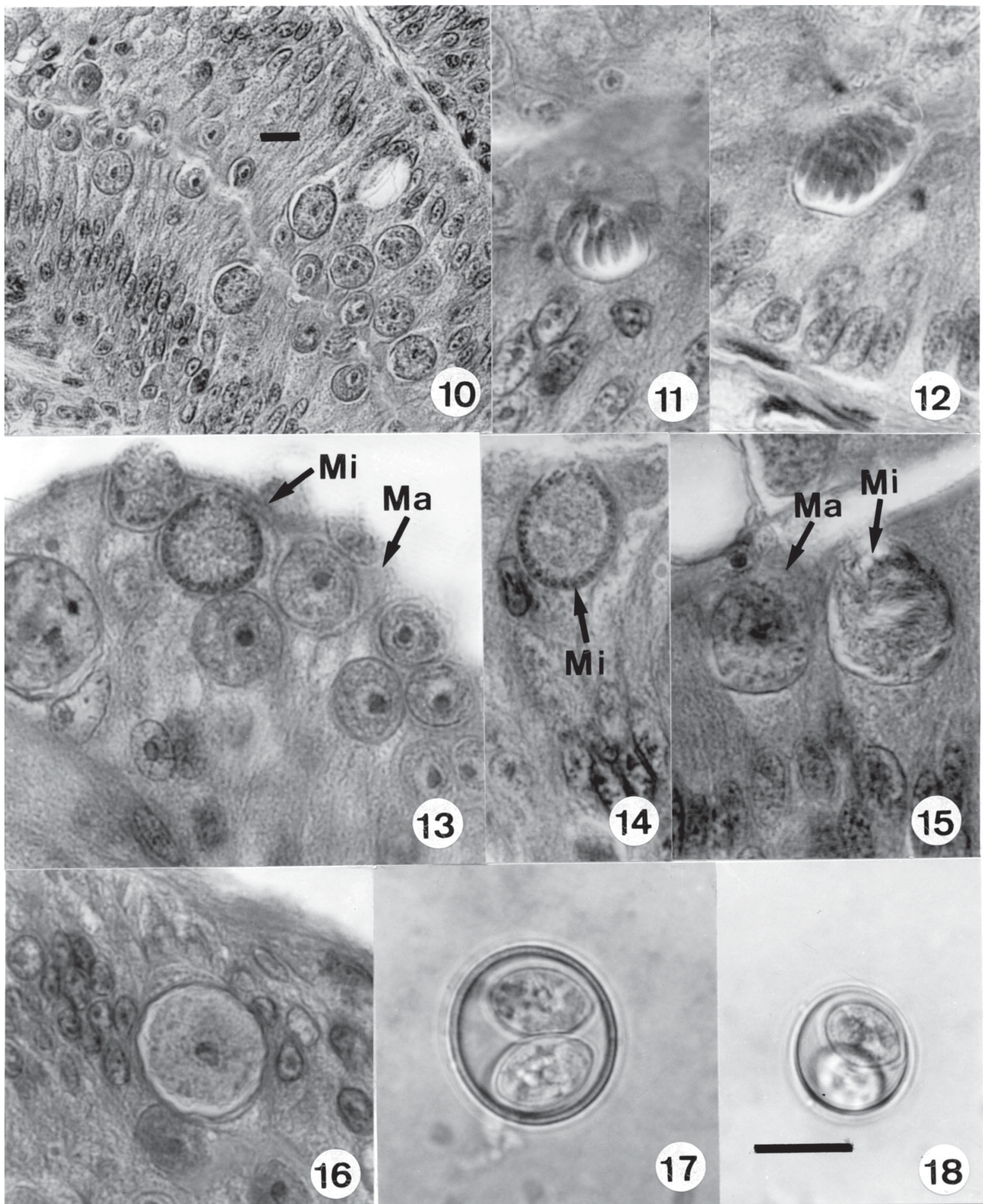

Figs 10-18. Isospora capanemaensis $\mathrm{n}$. sp. in the ileum epithelium of the lizard Amphisbaena alba. Fig. 10: low power view showing large number of developing parasites. Figs 11, 12: segmented meronts. Figs 13, 14: developing macrogamonts (Ma) and microgamonts with peripherally disposed nuclei (Mi). Fig. 15: mature macrogamont (Ma) and microgamont shedding microgametes (Mi). Fig. 16: intracellular zygote, or young oocyst, with oocyst wall already formed. Figs 17, 18: living, mature oocysts, showing extremes of the wide size range. Bars: $10 \mu \mathrm{m}$. Bar in Fig. 18 applies to Figs 11-18. Figs 10-16, sections stained with haematoxylin and eosin. 
develops in the parasite, which becomes packed with amylopectin granules: mature macrogamonts measure approximately $20 \times 17$. Latterly a smaller number of large wall-forming bodies make their appearance and the zygote, or young oocyst, now assumes a more elongate shape (Fig. 5). Mature oocysts are released and accumulate in large numbers in the bile (Fig. 8).

Sporulation: endogenous: predominantly in the lumen of the gall-bladder, but also in the intestine prior to being voided in the faeces.

Host: A. alba Linnaeus (Reptilia: Amphisbaenia: Amphisbaenidae).

Type locality: Capanema, state of Pará, North Brazil. Type material: histological sections of the endogenous stages in the author's collection at the Instituto Evandro Chagas.
Prevalence: 5 infections were recorded in $10 \mathrm{~A}$. alba examined (50\%).

Pathology: although all the infected lizards were of healthy appearance, heavy infections may involve all of the gallbladder epithelium, which suffers extensive damage (Fig. 2). Etymology: the specific name is derived from the generic name of the host.

\section{Isospora capanemaensis $\mathrm{n}$. sp.}

(Figs 10 - 18; 30 - 33)

Description of the oocyst: mature forms $14.8 \times 14.5(13.3$ - 18 x 12.6 - 16.3), shape-index $1.0(1.0$ - 1.1), $\mathrm{n}=30$. Subspherical to spherical. Wall of oocyst a smooth, colourless and single-layered membrane of approximately 1.5 , with no micropyle or striations and which easily becomes distorted with age or by pressure under a co-

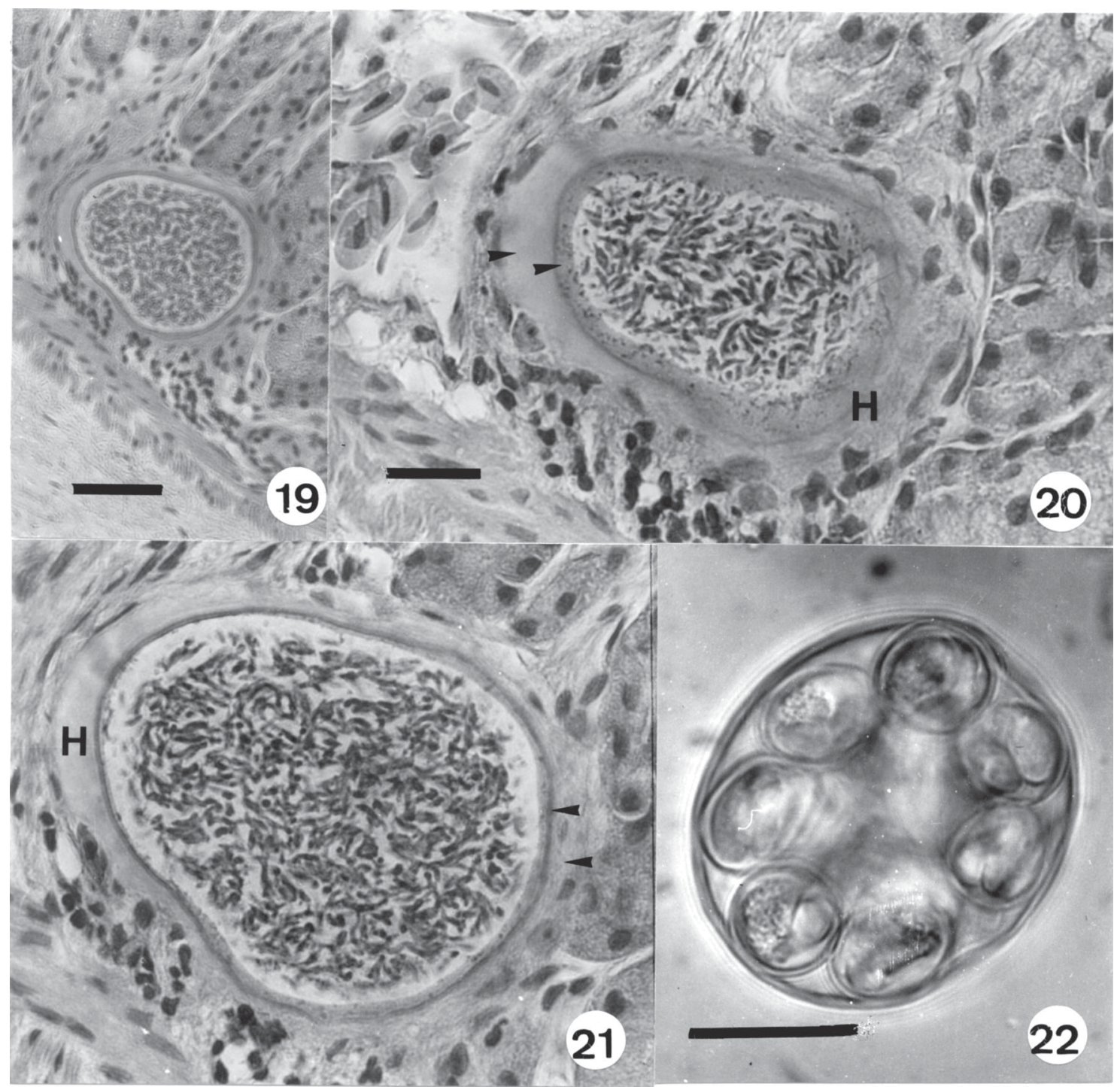

Figs 19-22. Unidentified coccidial parasites of the lizard Amphisbaena alba. Fig. 19: low power view showing location of a globidium in the lamina propria of the small intestine. Bar: $50 \mu \mathrm{m}$. Figs 20, 21: increased magnification to show the very large number of merozoites and the encompassing remnants of the host cell $(\mathrm{H})$ : note differences in the consistency of the inner and outer layers of the host cell cytoplasm (arrow-heads). Bar in Fig. 20: $20 \mu \mathrm{m}$ and applies to Fig. 21. Fig. 22: a multisporocystic oocyst passed in the faeces of $A$. alba, and possibly a spurious parasite originating from an item in the lizard's diet. Bar: $10 \mu \mathrm{m}$. Figs 19-21, sections stained with haematoxylin and eosin. 
verslip. No oocyst residuum or polar body. The two tetrazoic sporocysts are pear-shaped, with an inconspicuous Stieda body, and measure 8.6 x 6.6 (7.4 - 10.4 x 5.97.4), shape-index $1.3, \mathrm{n}=50$. The sporozoites are strongly re-curved about a residuum consisting of only 4-5 small, scattered globules. Refractile bodies were not visible.

Endogenous stages: intracytoplasmic in the epithelial cells of the ileum, above the host-cell nucleus. Mature meronts from $8 \times 8-13 \times 8$ and producing from $6-10$ merozoites (Figs 11, 12). Young microgamonts of $10 \times 10-12 \times 10$ have the nuclei localized at the periphery of the parasite (Figs 13, 14); mature forms (Fig. 15) measure approximately 14.0 $\mathrm{x} 12$ and produce a large number of microgametes $(>50)$. With growth, young macrogamonts of $5 \times 5$ attain a mature size of $12 \times 11$ : they have a nucleus with a conspicuous nucleolus (Fig. 13) and very inconspicuous wall-forming bodies. Intracellular zygotes, or young oocysts, measure $14 \times 12$ and the oocyst wall is already apparent (Fig. 16). Sporulation: exogenous, and completed 3 days after oocysts are voided in the faeces.

Host: the lizard A. alba Linnaeus (Reptilia: Amphisbaenia: Amphisbaenidae).

Type locality: Capanema, state of Pará, North Brazil. Type material: histological sections of the endogenous stages in the author's collection at the Instituto Evandro Chagas.

Prevalence: of the $10 \mathrm{~A}$. alba examined, $6(60 \%)$ were infected: 5 of these had concomitant infection with $C$. amphisbaena $\mathrm{n}$. sp.
Pathology: although infection may be intense, with much of the ileum affected (Fig. 10), the lizards showed no outward signs of ill-effects.

Etymology: the specific name is derived from the locality in which the infected lizards were obtained.

\section{A globidium-like parasite of the lizard Amphisbaena alba}

(Figs 19-21)

A single, fully developed globidium-like cyst was encountered in the lamina propria of the ileum of one specimen of $A$. alba, and no similar bodies could be detected elsewhere in the intestine or in other tissues of the lizard. It measured $105 \times 85$ at the largest cross-section, and contained many hundreds of merozoites of about 10 $12 \times 2-3$. The hypertrophied host cell was reduced to a hyaline coating showing inner and outer layers of different consistency (Figs 20,21) and containing what appeared to be the remnants of nuclei. The same animal was infected with I. capanemaensis $\mathrm{n}$. sp., C. amphisbaena $\mathrm{n}$. sp. and the unidentified parasite of the kidney, described below.

\section{An unidentified, multisporocystic oocyst of Amphisbaena alba}

(Figs 22; 34-37)

Description of the oocyst: mature forms $22.2 \times 21.4(19.4$ 27 x 17.5 - 25), shape-index $1.0(1-1.1), \mathrm{n}=30$. Subspherical to spherical. Wall approximately 1.0 , smooth, colourless to faintly brown. It is apparently of a single

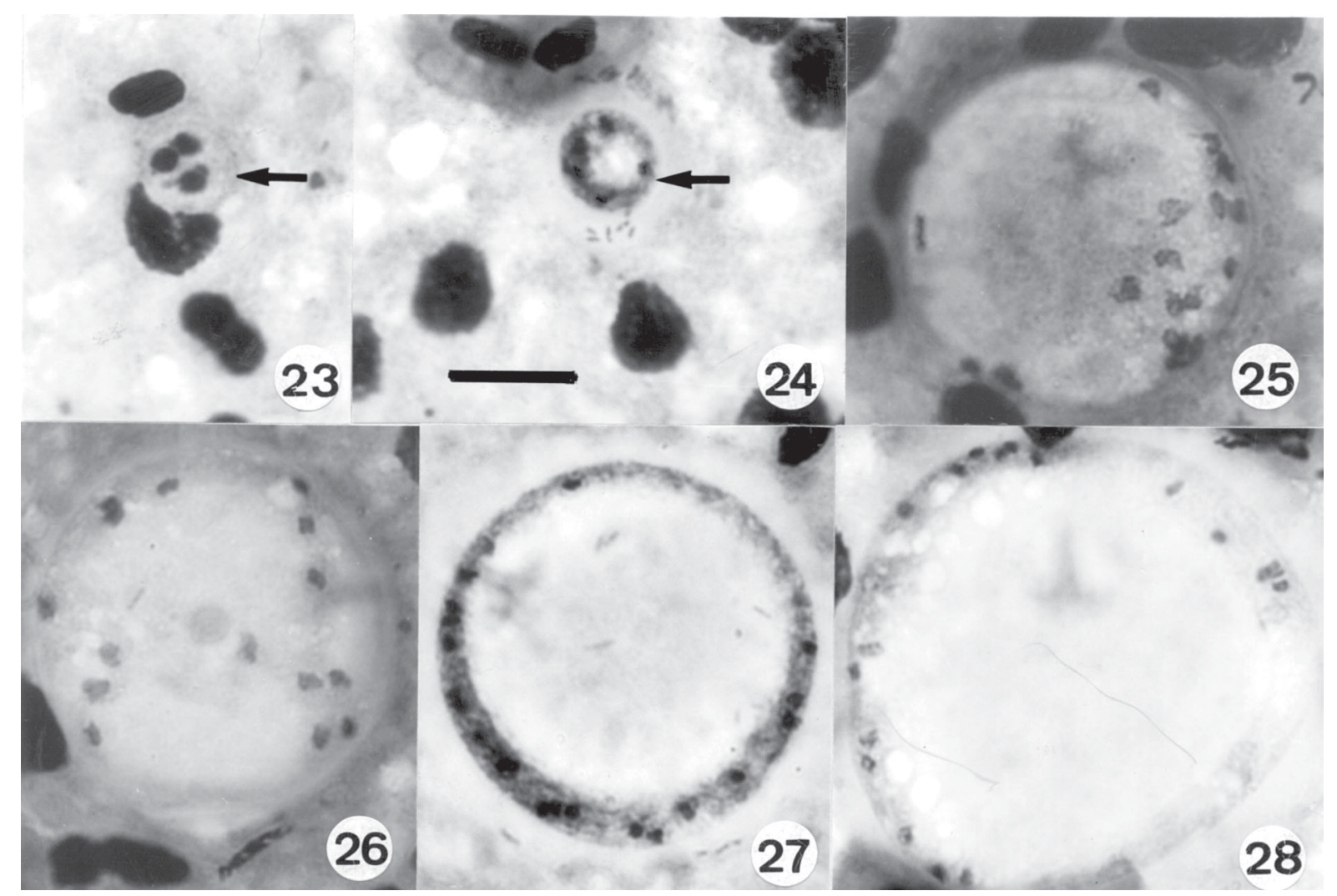

Figs 23-28. An unidentified parasite in the kidney of the lizard Amphisbaena alba. Figs 23, 24: young intracellular and extracellular forms with 3-6 nuclei (arrowed). Figs 25, 26: developmental stages with increasing number of nuclei. Figs 27, 28: cyst-like stages with a large central vacuole and a peripheral rim of cytoplasm containing the nuclei. Bar: $10 \mu \mathrm{m}$. Giemsa-stained dab-smear of kidney 
layer, with no micropyle or striations and often becomes deformed or broken (Fig. 37). There is no oocyst residuum. Oocysts with from $2-10$ sporocysts measuring $8.1 \times 5.6$ $(7.5-10 \times 5-7.5)$, shape-index $1.4, \mathrm{n}=32$ : they are ovoid to pear-shaped and often deformed into triangular or other irregular shapes. No Stieda body or other localized thickening of the sporocyst wall. Sporocysts with 2 recurved sporozoites of approximately 6.2 x 1.7 ; no refractile bodies could be detected. There is a bulky sporocystic residuum of fine granules and globules.

Sporulation: in the same faecal sample, oocysts were voided unsporulated (Fig. 34), at the sporoblast stage (Fig. 35), or fully sporulated (Fig. 36).

An unidentified parasite in the kidney of Amphisbaena alba

(Figs 23 - 28)

These were detected in a kidney smear of one A. alba. The earliest stage seen, apparently within a macrophage, measured $7 \times$ 7: 3 heavily stained nuclei were present in the cytoplasm, which stained a pale blue (Fig. 23). Other extracellular forms, of the same size, showed the cytoplasm to have condensed into a periperal ring-like mass surrounding a central vacuole, and containing from 4-6 nuclei

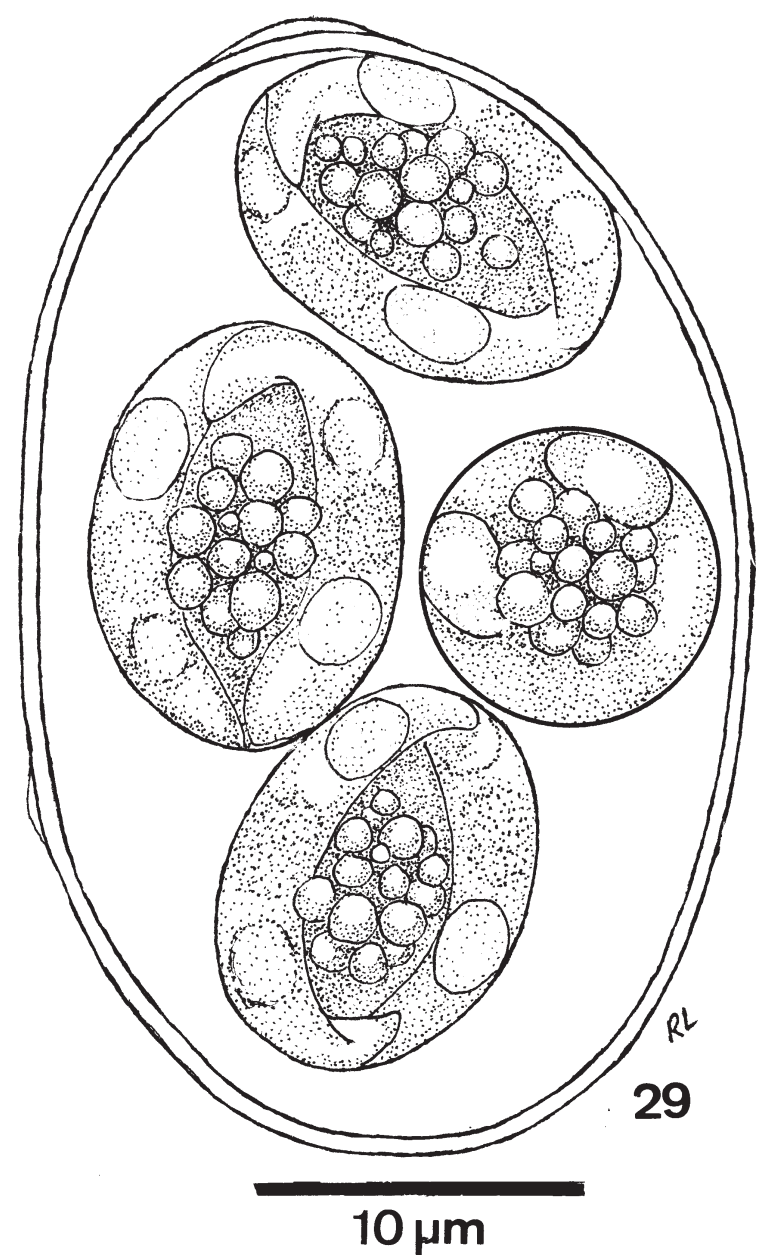

Fig. 29: Choleoeimeria amphisbaenae n. sp., of the lizard Amphisbaena alba. Line-drawing of mature oocyst in the bile: note separation of the two oocysts wall layers in two places.
(Fig. 24). Growth of the parasites finally produced relatively large cyst-like bodies measuring 28 x 27.1 (22.2 $37 \times 20.7$ - 35), shape-index $1.0, \mathrm{n}=12$, characteristically with a very large central vacuole encompassed by a narrow band of well-stained cytoplasm containing from 8-20 nuclei (Figs 27, 28).

\section{DISCUSSION}

In 1926, Carini and Pinto found oocysts in the bile of the gecko Hemidactylus mabouia (Gekkonidae) and, by reason of the parasite's tetrasporocystic/dizoic morphology, placed it in the genus Eimeria as E. rochalimai. Following a study of this coccidian's endogenous development in the gall-bladder epithelium, Lainson and Paperna (1999a) transferred the parasite to the genus Choleoeimeria Paperna \& Landsberg, 1989 and, in the same paper, described a further species of the genus in the teiid lizard Ameiva ameiva as $C$. carinii.

Oocysts of all the described species of Choleoeimeria do share basic characteristics in their endogenous sporulation in the gall-bladder, their elongated oocysts, and the presence of 4 dizoic sporocysts which lack Stieda and sub-Stieda bodies and possess a bi-valved structure. It is the general belief that the same species of coccidia are unlikely to occur in hosts belonging to different families, and this alone might be considered a sufficient reason for the separation of C. rochalimai of Hemidactylus mabouia (Gekkonidae), C. carinii of A. ameiva (Teiidae) and C. amphisbaenae n. sp of A. alba (Amphisbaenidae). In addition, oocysts of C. rochalimai frequently possess a conspicuous polar body, and those of C. carinii contain numerous fine granules. Oocysts of C. amphisbaenae were not found to contain such inclusions: they are larger and less elongated than those of the other 2 species, i.e. $33.7 \times 22.8$, shape-index 1.5 versus $29.1 \times 17.8$, shape-index 1.6 for $C$. rochalimai, and 32 x 17.8, shape-index 1.8 for C. carinii. Sporocysts of $C$. amphisbaenae are the largest of the 3 parasites, i.e. $13 \mathrm{x}$ 9.3 versus $9 \times 7.5$ and $11 \times 8.8$. Differences in the endogenous stages are less conspicuous, but in histological sections the mature meronts of $C$. amphisbaenae are small and produce fewer merozoites than the other 2 species, i.e. $15 \times 14$, with up to 12 merozoites versus $29 \times 13$, with up to 75 merozoites and 23-26 x 18-21, with up to 19 merozoites.

The surprisingly wide size range of the oocysts and sporocysts of I. capanemaensis n. sp (Figs 17,18) at first gave the impression that there were 2 distinctly different Isospora species. Analysis of the measurements, however, showed there to be a steady gradation in size from the smallest to the largest. Once again, the possibility that $I$. capanemaensis is conspecific with a parasite described in other families of New World lizards is considered very unlikely. In comparing it with some species described in lizards from the same area of North Brazil, there are the following differences: I. ameivae Carini, 1932 (redescription, Lainson \& Paperna 1999b), and $I$. cnemidophori Carini, 1942 of A. ameiva and Cnemidophorus lemniscatus lemniscatus (Teiidae) have much larger oocysts and sporocysts, and both possess a conspicuous polar body. I. hemidactyli Carini, 1936 (re- 
description Lainson \& Paperna 1999b) of H. mabouia (Gekkonidae) also has larger oocysts and sporocysts, and a polar body. In addition, its endogenous development is within the nucleus of the epithelial cells of the small intestine.

No endogenous stages were found that could be attributed to the multisporocystic oocysts passed by $A$. $a l b a$, and 2 specimens of this lizard that had been forcefed with a suspension of washed oocysts failed to show any such parasites in their faeces collected 2 and 4 weeks later. This leads one to suspect that the oocysts were merely passing through the intestine of the lizard following their ingestion within some invertebrate host that the animal had eaten. I have noted similar multisporocystic oocysts in the faeces of the anteater Tamandua tetradactyla, the "crab-eating fox" Cerdocyon thous, the tortoise Geochelone denticulata, the lizard A. ameiva and an unidentified frog. A feature that these oocysts have in common is the very variable number of sporocysts they contain. Also notable is the fact that all of the animals in which they have been found commonly consume adult and larval termites, ants, beetles and other invertebrates. A search for these enigmatic oocysts in such food items might well be rewarding.

Doubts regarding the taxon Globidium Flesch, 1883 have been discussed at length by Pellerdy (1974) and Paperna (1999). Globidia have been described in the lamina propria of the digestive tract in sheep, goats, horses, marsupials, and armadillos, where they are generally considered to be giant meronts of certain intestinal coccidians, the species of which is very often uncertain. Among the reptiles, the only reports have been
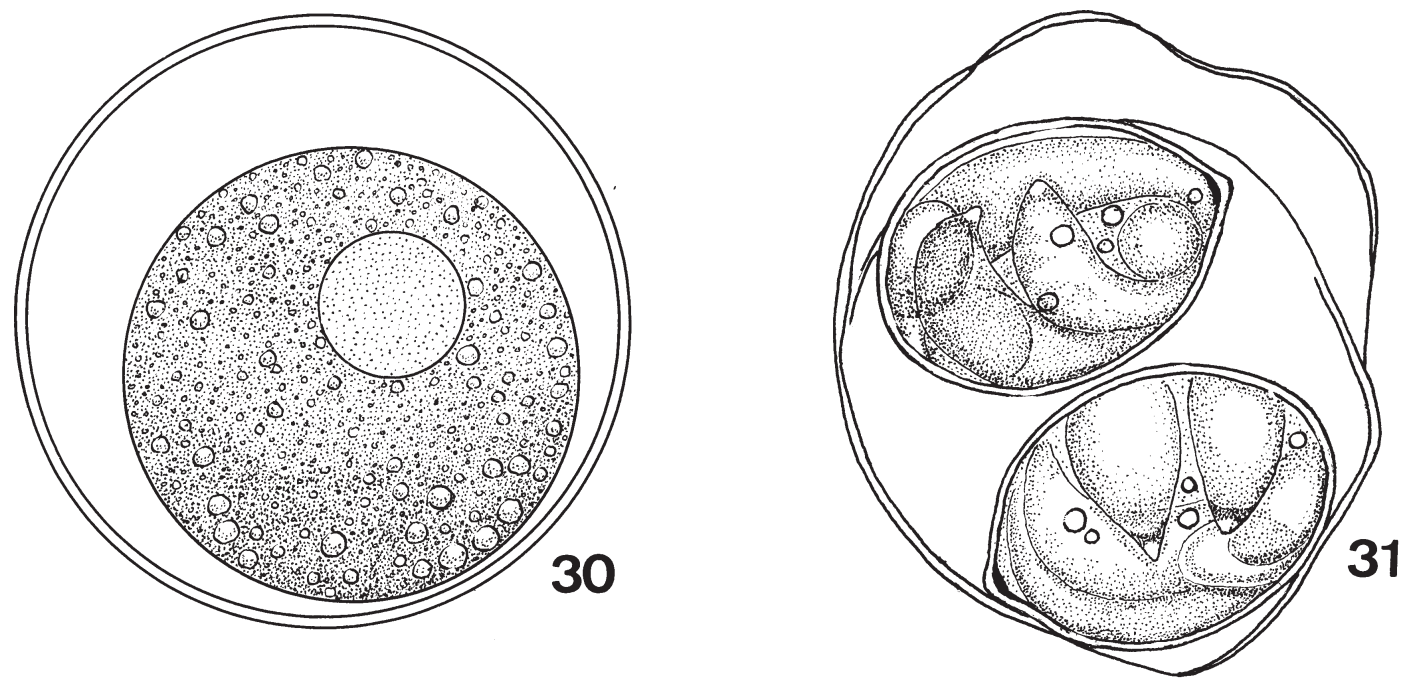

\section{$10 \mu \mathrm{m}$}
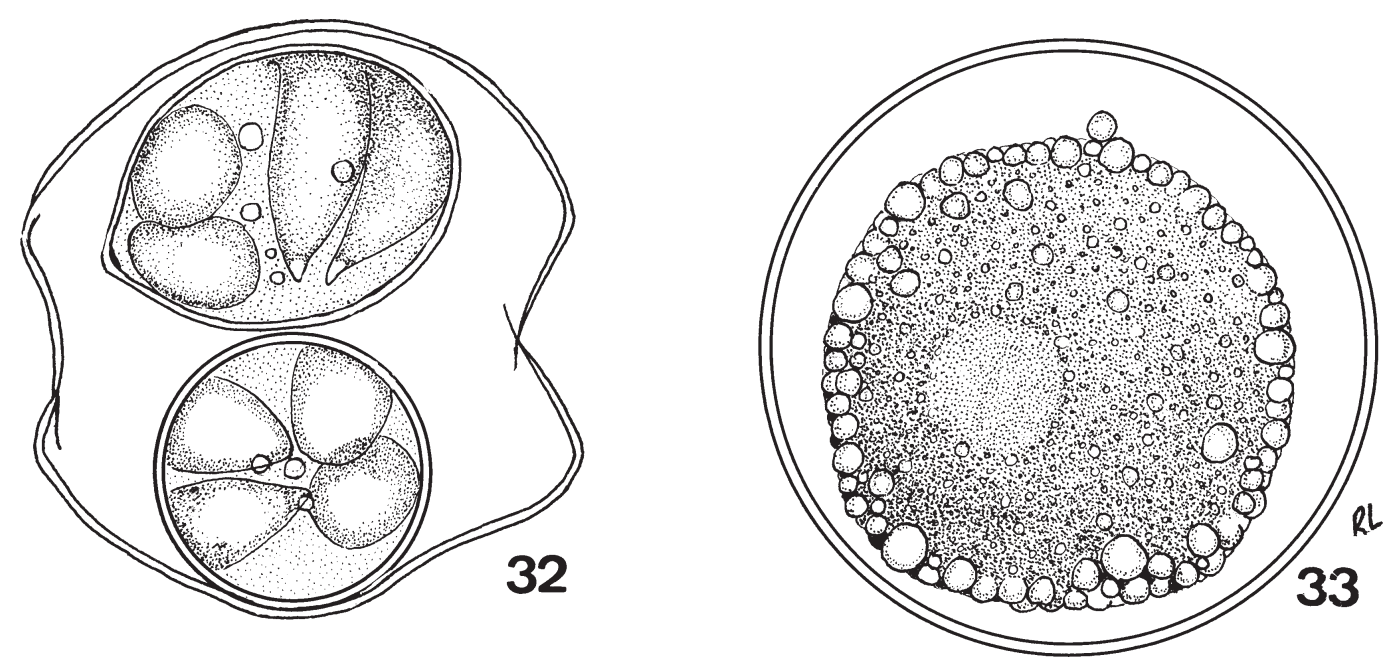

Figs 30-33: Isospora capanemaensis n. sp. of the lizard Amphisbaena alba. Line-drawings of unsporulated oocysts when freshly passed (Fig. 30), $36 \mathrm{~h}$ after being voided in the faeces (Fig. 33) and when fully sporulated at 3 days (Figs 31, 32). Mature oocysts are at first spherical or subspherical, but the delicate wall becomes deformed with age or by pressure under a coverslip. 
in a snake (Harant \& Cazal 1934) and the gekkonid lizard Heteronotia binoei (Paperna 1999). Superficially, globidia closely resemble the tissue cysts of Besnoitia, with the important difference that multiplication in the latter is by endodyogeny, whereas that of eimeriid coccidians is by the budding of merozoites from the meront cytoplasm. Paperna (1999) was able to differentiate the globidium of H. binoei from Besnoitia by the absence of endodyogeny in developmental stages of the parasite. Unfortunately only a single, fully developed globidium was found in the small intestine of $A$. alba, and the process of multiplication could not be determined. Besnoitia cysts are usually found widely distributed in the skin and on the surface of the visceral organs, where they develop in connective tissue cells. No such bodies could be found in A. alba, however, and this mitigates against the parasite in the lamina propria of this lizard being a species of Besnoitia. It is of interest that the globidia of $H$. binoei and A. alba were both found in lizards infected with Isospora species, and the possibility that they are unusual developmental stages of these coccidia has to be considered.

The parasite in the kidney of $A$. alba remains to be identified and it is as yet uncertain if it is protozoal or fungal. No segmentation products or other developmental stages were found, and the exact location of the organism in the kidney has still to be ascertained.
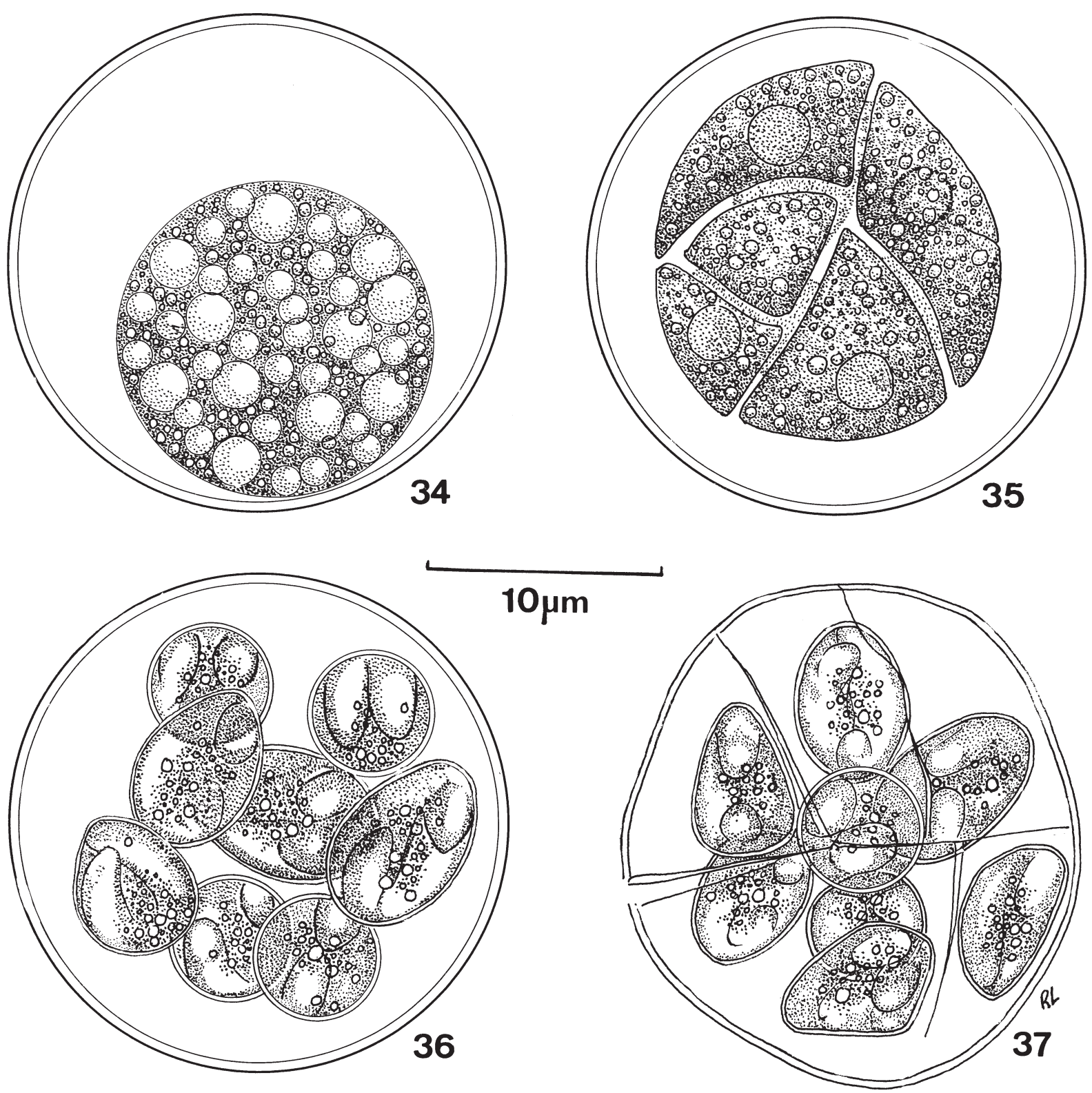

Figs 34-37: line-drawings of an unidentified, multisporocystic oocyst voided in the faeces of the lizard Amphisbaena alba. Oocysts in the same faecal sample were passed completely unsporulated (Fig. 34), at the sporoblast stage (Fig. 35) or fully sporulated (Fig. 36). The wall is fragile and easily broken (Fig. 37). 


\section{ACKNOWLEDGEMENTS}

To Constância M Franco, Manoel C de Souza, and Antonio $\mathrm{J}$ de Oliveira Monteiro for technical assistance. Histological sections were prepared by Walter M Campos.

\section{REFERENCES}

Carini A, Pinto C 1926. Estudos sobre coccídeos. Arch Biol São Paulo 11: 83-86.

Harant H, Cazal P 1934. Remarques sur le genre Globidium: Globidium navillei n. sp. Parasite de la couleuvre. Ann Parasitol Hum Comp 12: 162-169.

Lainson R, Paperna I 1999a. Some Coccidia from the gall-bladder and intestine of the Teiid lizard Ameiva ameiva ameiva and the gecko Hemidactylus mabouia in north Brazil. Parasite 6: $151-162$.

Lainson R, Paperna I 1999b. Re-descriptions of Isospora ameivae Carini, 1932 in the Teiid lizard Ameiva ameiva and Isospora hemidactyli Carini, 1936 in the gecko Hemidactylus mabouia, with particular reference to their endogenous stages. Mem Inst Oswaldo Cruz 94: 459-466.

Paperna I 1999. Globidia infection in the gut of an Australian gecko Heteronotia binoei. Folia Parasitol 46: 175-178.

Paperna I, Landsberg JH 1989. Description and taxonomic discussion of eimerian Coccidia from African and Levantine geckoes. S Afr J Zool 24: 345-355.

Pellerdy LP 1974. Coccidia and Coccidiosis, Verlag Paul Parey, Berlin, Hamburg, 959 pp.

Pessoa SB 1968. Sobre uma hemogregarina da Amphisbaena alba. Gaz méd Bahia 68: 75-78.

Peters JA, Donoso-Barros R 1970. Catalogue of the Neotropical Squamata: Part II. Lizards and Amphisbaenians, US Nat Mus Bulletin 297, Smithsonian Inst Press, Washington, 293 $\mathrm{pp}$.

Telford SR 1984. Haemoparasites of reptiles. In GL Hoff, FL Frye, ER Jacobson (eds), Diseases of Amphibians and Reptiles, Plenum Publishing Corporation, US. 